\title{
PHYTOCHEMICALS, ANTIOXIDANT ACTIVITY AND PHENOLIC PROFILING OF DIPLOCYCLOS PALMATUS (L.) C. JEFFERY
}

\author{
USMANGANI A. ATTAR, SAVALIRAM G. GHANE* \\ Department of Botany, Shivaji University, Kolhapur 416004, Maharashtra, India \\ Email: sgg.botany@unishivaji.ac.in
}

Received: 02 Jan 2017 Revised and Accepted: 14 Feb 2017

\begin{abstract}
Objective: The aim of this study was to analyze phytochemicals, antioxidant potential and phenolic profiling of leaf and fruit extracts of Diplocyclos palmatus.

Methods: The leaves and fruits were subjected for sequential extraction with hexane, chloroform, methanol and water. All extracts were subjected to biochemical studies such as phenols, tannins, flavonoids, terpenoids and antioxidant assays such as 1,1-diphenyl-1-picryl hydrazyl (DPPH), 2,2' Azinobis (3-ethyl-benzothiozoline-6-sulfonic acid (ABTS), ferric reducing antioxidant property (FRAP), metal chelating and phospho- molybdenum reduction assay. Further methanolic extract was used for phenolics characterization by reversed phase-high performance liquid chromatography (RP-HPLC)

Results: It was observed that methanol fruit extract showed significantly higher phenolics ( $9.29 \pm 0.01 \mathrm{mg}$ tannic acid equivalent (TAE)/g extract), flavonoids (15.02 $\pm 0.96 \mathrm{mg}$ catechin equivalent (CE)/g extract) and terpenoids (276.73 $\pm 0.76 \mathrm{mg}$ ursolic acid equivalent (UAE)/g extract). However, chloroform extracts of leaf and fruit exhibited a high amount of tannins $(22.07 \pm 0.06,6.99 \pm 0.10 \mathrm{mg}$ CE/g extract) respectively. The extracts were subjected to assess their antioxidant potential using various in vitro systems such as DPPH, ABTS, FRAP, metal chelating and phospho- molybdenum reduction. Among the various extracts, methanol fruit extract had highest DPPH radical scavenging activity (26.73 \pm 0.14 mg ascorbic acid equivalent $(\mathrm{AAE}) / \mathrm{g}$ extract), metal chelating activity $(0.80 \pm 0.01 \mathrm{mg}$ EDTA equivalent (EE)/g extract) and phospho- molybdenum activity (291.24 $\pm 2.19 \mathrm{mg}$ $\mathrm{AAE} / \mathrm{g}$ extract). In ABTS radical scavenging assay, aqueous leaf extract (12.11 $\pm 0.07 \mathrm{mg}$ trolox equivalent (TE)/g extract) showed the best response. The effective ferric reducing antioxidant property (141.54 $\pm 10.12 \mathrm{mg}$ Fe (II)/g extract) was exhibited by aqueous fruit extract. Overall, methanol and water were found to be the best solvents for the extraction of antioxidant compounds from fruit and leaf. In the RP-HPLC analysis, the major bioactive phenolic compounds such as catechin (CA) and hydroxybenzoic acid (HBA) were recorded in leaf as compared to fruit. In leaf, CA and chlorogenic acid (CLA) were principal compounds in leaf and fruit respectively. However, gallic acid (GA), HBA, CLA and vanillic acid (VA) were widespread in leaf and fruit.
\end{abstract}

Conclusion: On the basis of the results, it was found that D. palmatus may serve as a novel and rich source of natural antioxidants and it can be further explored for pharmaceutical purposes.

Keywords: Diplocyclos palmatus, Antioxidant, Reactive oxygen species, RP-HPLC

(c) 2017 The Authors. Published by Innovare Academic Sciences Pvt Ltd. This is an open access article under the CC BY license (http://creativecommons.org/licenses/by/4.0/) DOI: http://dx.doi.org/10.22159/ijpps.2017v9i4.16891

\section{INTRODUCTION}

Plants have been used as a source of food and medicine from the beginning of civilization. They are a diverse source of nutrients and bioactive compounds that are valuable for human health. Many ethano-botanical surveys and traditional knowledge of medicinal plant has been proved their significance in curing various diseases [1]. In recent year, interest has been focused on plant-based antioxidant compounds due to their safer and non-toxic nature. Plants contain various phytochemicals that showed antioxidant properties like phenolics, flavonoids, carotenoids, vitamins, terpenoids and nitrogenous compounds [2]. Antioxidants are those compounds which have the ability to neutralize the harmful effects of reactive oxygen species (ROS) and protect the biological system from possible deterioration [3]. Generally, ROS are generated in both plant and animal as a part of normal cell metabolism and play an important role in various cell signaling pathway and gene expression. Overproduction of ROS leads to oxidative stress and subsequent damages of biological molecules such as lipids, proteins and nucleic acids [4]. Furthermore, they also play a significant role in development and progression of many chronic diseases like ageing, arthritis, carcinogenesis, diabetes, mellitus, cardiovascular, respiratory, kidney, malignant tumors, cataracts, hypertension, atherosclerosis, Parkinson's and Alzheimer's diseases [5]. Among the natural antioxidants, phenolics are widely distributed a group of compounds in the plant kingdom. Several studies have proved that phenolic compounds are directly associated with the antioxidant activities and have diverse health benefits in the prevention of various oxidative stress related diseases [6].

Diplocyclos palmatus (Family Cucurbitaceae) is neglected medicinal plant commonly called as Shivalingi and Lollipop climber. Leaves and fruits are eaten as a vegetable in Kenya and South-East Asia. The different parts of the plant have been used by the traditional practitioner for curing various ailments. The fruits are laxative, expectorant and mainly used in reproductive medicines to treat impotency, female infertility and leucorrhoea. Seeds are aphrodisiac, febrifuge, anti-inflammatory and used for promoting conception in women $[7,8]$. It is also used in the treatment of a cough, flatulence, rheumatic pain, asthma, skin diseases and snakes bite. Plant possess gynaecological, anticonvulsant, anti-venom, antidote, antimicrobial, antidermatophytic, analgesic and anti-arthritic properties [9-12].

In earlier studies, work has been done mostly on pharmacological activities, but no reports are available on its phytochemicals and antioxidant properties. In this respect, the aim of the present investigation was to analyze the chemical constituents (phenolics, tannins, flavonoids, terpenoids) and antioxidant activities such as DPPH, ABTS, FRAP, metal chelating and phospho- molybdenum reduction using leaf and fruit extracts. Furthermore, characterization of phenolics was also carried out using reversed phase-high performance liquid chromatography (RP-HPLC) from methanolic extracts of leaf and fruit. 


\section{MATERIALS AND METHODS}

\section{Chemicals and reagents}

GA, CA, HBA, CLA, VA, UA and trolox were purchased from SigmaAldrich (St. Louis, Mo, USA). DPPH, ABTS, ethylene-diamine tetraacetic acid (EDTA), 2,4,6-tripyridyl-2-triazine (TPTZ), ascorbic acid, ferrous chloride, ferrozine, ferric chloride, ferrous sulphate, sodium phosphate, ammonium molybdate, hydrochloric acid, sulfuric acid and solvents such as hexane, chloroform, ethanol, methanol were purchased from Sisco research laboratory Pvt. Ltd., Mumbai. All the reagents used were of analytical grade.

\section{Preparation of solvent extracts}

Leaves and fruits were collected freshly during the month November 2014 from Kolhapur, Maharashtra, India. The location lies between N16 ${ }^{\circ} 40^{\prime} 51.99^{\prime \prime}$ Latitude and E74'15'13.33" Longitude. Collected plant samples were washed under running tap water and dried in hot air oven at $50{ }^{\circ} \mathrm{C}$ for $72 \mathrm{~h}$. Oven dried plant samples were ground into fine powder using spice mill. Powdered samples were used for sequential extraction with hexane, chloroform, methanol and water using maceration method. About $20 \mathrm{~g}$ of powder was added in a known volume of respective solvent and allowed for shaking $(12 \mathrm{~h}$, $100 \mathrm{rpm}, 30{ }^{\circ} \mathrm{C}$ ) on orbital shaker incubator (Allied Scientific Products, India). After filtering through filter paper, centrifuged at $5,000 \mathrm{rpm}$ for $15 \mathrm{~min}$ to remove debris. The supernatant was kept at room temperature for complete evaporation of the solvent. Finally, dried extracts were weighed, dissolved in a known volume of respective solvents and kept at $4{ }^{\circ} \mathrm{C}$ until used for analysis. The extract recovery from various solvent was expressed in percent (\%).

\section{Total phenolics}

Total phenolics content were determined by the method described by Singleton and Rossi [13]. A known volume of plant extract $(100 \mu \mathrm{l})$ was mixed with $2 \mathrm{ml}$ of pre-diluted (1:10) Folin and Ciocalteu reagent. After $5 \mathrm{~min}$ incubation at room temperature, $0.8 \mathrm{ml}$ of $(7.5 \% \mathrm{w} / \mathrm{v})$ sodium carbonate $(7.5 \% \mathrm{w} / \mathrm{v})$ was added. The reaction mixture was shaken thoroughly and allowed to stand for $60 \mathrm{~min}$ at room temperature. The absorbance was taken at $765 \mathrm{~nm}$ using UV-visible spectrophotometer (Shimadzu UV-1800, Japan). A calibration curve was plotted using a standard solution of tannic acid $(20-120 \mu \mathrm{g} / \mathrm{ml})$. Total phenolics were expressed as mg TAE/g extract $\left(\mathrm{R}^{2}=0.989\right)$.

\section{Total tannins}

Total tannins were estimated by using the vanillin- $\mathrm{HCl}$ method with minor modification [14]. Plant extract $(100 \mu \mathrm{l})$ were mixed separately with $2 \mathrm{ml}$ of reagent consist of $4 \%(\mathrm{w} / \mathrm{v})$ vanillin in methanol and $8 \%(\mathrm{v} / \mathrm{v}) \mathrm{HCl}$ in methanol (1:1 ratio). The mixture was allowed to stand for $20 \mathrm{~min}$ incubation, and the absorbance of samples was measured at $500 \mathrm{~nm}$. Catechin solution $(50-300 \mu \mathrm{g} / \mathrm{ml})$ was used for the preparation of calibration curve. The amount of total tannins content was expressed as mg CE/g extract $\left(R^{2}=0.990\right)$.

\section{Total flavonoids}

Total flavonoids were estimated by the following method of Sakanaka et al. [15]. Plant extract $(50 \mu \mathrm{l})$ was taken into a test tube, and volume was made to $(0.5 \mathrm{ml})$ with distilled water followed by addition of $75 \mu \mathrm{l}$ of $5 \%(\mathrm{w} / \mathrm{v})$ sodium nitrite solution. After $6 \mathrm{~min}$ incubation, $150 \mu \mathrm{l}$ of $10 \%(\mathrm{w} / \mathrm{v})$ aluminium trichloride solution was added and incubated at room temperature for $5 \mathrm{~min}$. Further, $0.5 \mathrm{ml}$ of $1 \mathrm{M}$ sodium hydroxide was added and final volume made up to 2 $\mathrm{ml}$ with distilled water. The absorbance was read immediately at $510 \mathrm{~nm}$. Different concentrations of $(50-300 \mu \mathrm{g} / \mathrm{ml})$ of catechin were used to prepared standard curve. The amounts of total flavonoids were expressed as mg CE/g extract $\left(\mathrm{R}^{2}=0.990\right)$.

\section{Total terpenoids}

Total terpenoids content was determined by the spectroscopic method described by Chang and Lin [16]. Plant material (100 $\mu \mathrm{l})$ from each solvent extracts was mixed with $150 \mu$ freshly prepared 5 $\%(\mathrm{w} / \mathrm{v})$ vanillin in glacial acetic acid and $500 \mu \mathrm{l}$ perchloric acid. All the reaction mixture was heated for $45 \mathrm{~min}$ at $60^{\circ} \mathrm{C}$ then cooled in ice bath. Further, $2.25 \mathrm{ml}$ glacial acetic acid was added to the reaction mixture and absorbance was measured at $548 \mathrm{~nm}$. UA (25$500 \mu \mathrm{g} / \mathrm{ml}$ ) was used for the preparation of calibration curve. The amount of total terpenoids content was expressed as mg UAE/g extract $\left(R^{2}=0.987\right)$.

\section{Antioxidant assays}

\section{DPPH· radical scavenging activity}

DPPH radical scavenging activity was measured according to the method of Brand-Williams et al. [17]. A methanolic solution of DPPH $(0.025 \mathrm{~g} / \mathrm{l})$ was prepared freshly. Aliquot of plant extract $(1 \mathrm{ml})$ of different concentrations $(25-300 \mu \mathrm{g} / \mathrm{ml})$ were added to $3 \mathrm{ml}$ of DPPH solution. Reaction mixtures were kept in the dark for $30 \mathrm{~min}$ and a decrease in absorbance was measured at $515 \mathrm{~nm}$. Activities were measured using a standard curve obtained from various concentrations of ascorbic acid $(20-100 \mu \mathrm{g} / \mathrm{ml})$ and it expressed in $\mathrm{mg} \mathrm{AAE} / \mathrm{g}$ extract $\left(\mathrm{R}^{2}=0.990\right)$.

\section{ABTS+radical scavenging activity}

ABTS-+radical scavenging activity was carried out using the method of Re et al. [18]. ABTS radical cation produced by reacting $7 \mathrm{mmol}$ aqueous solutions of ABTS with an aqueous solution of $2.45 \mathrm{mmol}$ potassium per sulfate. Further reagent mixture was allowed to stand for $12-16 \mathrm{~h}$ at room temperature. The reagent solution was diluted in ethanol $(1: 89 \mathrm{v} / \mathrm{v})$ and equilibrated at $30^{\circ} \mathrm{C}$ to give absorbance at $734 \mathrm{~nm}$ of $0.7 \pm 0.02$. Plant extract of different concentrations (20-60 $\mu \mathrm{g} / \mathrm{ml}$ ) were combined with $3 \mathrm{ml}$ of ABTS-+diluted solution. Absorbance was recorded after $30 \mathrm{~min}$ at $734 \mathrm{~nm}$. The calibration curve was obtained for trolox standard solution $(20-120 \mu \mathrm{g} / \mathrm{ml})$ and results were expressed as mg TE/g extract $\left(\mathrm{R}^{2}=0.996\right)$.

\section{Metal chelating activity}

The chelating of ferrous ion was estimated by the method of Dinis et al. [19]. Plant extract ( $40 \mu \mathrm{l}$ ) was mixed with $50 \mu \mathrm{l}$ of $2 \mathrm{mmol} \mathrm{FeCl}_{2}$. The reaction was initiated by adding $100 \mu \mathrm{l}$ of $5 \mathrm{mmol}$ ferrozine. The final volume of the reaction was made to $1500 \mu \mathrm{l}$ by adding distilled water and mixture was shaken vigorously. The absorbance was measured at $562 \mathrm{~nm}$ after $20 \mathrm{~min}$ incubation at room temperature. The chelating activity of the extract was estimated by using EDTA as standard $(20-120 \mu \mathrm{g} / \mathrm{ml})$. The results are expressed as $\mathrm{mg} \mathrm{EE} / \mathrm{g}$ extract $\left(R^{2}=0.995\right)$.

\section{FRAP assay}

The antioxidant properties in terms of FRAP were estimated according to the protocol of Benzie and Strain [20]. FRAP reagent prepared freshly and incubated at $37^{\circ} \mathrm{C}$ prior to use. FRAP reagent contained 2.5 $\mathrm{ml}$ of $10 \mathrm{mmol}$ TPTZ in $40 \mathrm{mmol} \mathrm{HCl}, 2.5 \mathrm{ml}$ of $\mathrm{FeCl}_{3} .6 \mathrm{H}_{2} \mathrm{O}$ and $25 \mathrm{ml}$ of $300 \mathrm{mmol}$ acetate buffer $(\mathrm{pH}$ 3.6). Plant extract $(150 \mu \mathrm{l})$ was allowed to react with $2850 \mu \mathrm{l} \mathrm{FRAP} \mathrm{reagent} \mathrm{and} \mathrm{incubated} \mathrm{at} 37^{\circ} \mathrm{C}$ for $30 \mathrm{~min}$. The increase in absorbance was measured at $593 \mathrm{~nm}$. A standard calibration curve was prepared using different concentrations (20-120 $\mu \mathrm{g} / \mathrm{ml}$ ) of $\mathrm{FeSO}_{4} .7 \mathrm{H}_{2} \mathrm{O}$. Results were expressed in $\mathrm{mg}$ Fe (II) equivalent/g extract $\left(\mathrm{R}^{2}=0.983\right)$.

\section{Phosphomolybdenum assay}

The phospho- molybdenum assay was performed by the method of Prieto et al. [21]. A known volume of plant extract $(100 \mu \mathrm{g} / \mathrm{ml})$ was mixed with $1 \mathrm{ml}$ reagent $(0.6 \mathrm{M}$ sulfuric acid, 28 mmol sodium phosphate and $4 \mathrm{mmol}$ ammonium molybdate). The vials were capped and incubated in water bath at $95{ }^{\circ} \mathrm{C}$ for $90 \mathrm{~min}$. After cooling the samples, absorbance was measured at $695 \mathrm{~nm}$ against blank. Different concentrations $(20-120 \mu \mathrm{g} / \mathrm{ml})$ of ascorbic acid in distilled water were used to plot calibration curve and antioxidant activity was expressed as mg AAE/g extract $\left(R^{2}=0.992\right)$.

\section{Qualitative and quantitative analysis of phenolic compounds by RP-HPLC}

\section{Preparation of sample and standard solution}

The dried powder of leaf and fruit (500 mg) with methanol $(10 \mathrm{ml})$ were kept on orbital shaker incubator at $110 \pm 2 \mathrm{rpm}\left(25^{\circ} \mathrm{C}, 48 \mathrm{~h}\right)$. The further mixture was filtered through Whatman filter No. 1 and centrifuged at $10,000 \mathrm{rpm}$ for $20 \mathrm{~min}$ at $4{ }^{\circ} \mathrm{C}$. Supernatant was 
collected and stored at $4{ }^{\circ} \mathrm{C}$ until HPLC analysis. Phenolic compounds such as GA, CA, HBA, CLA, VA and coumaric acid (COA) (SigmaAldrich, St. Louis, Mo, USA) were weighed accurately and dissolved separately in methanol to obtain a standard stock solution (1 $\mathrm{mg} / \mathrm{ml}$ ). Further, working stock solution was prepared by diluting the stock solution with methanol to get five different concentrations for calibration curves. All the stock and working stock solutions were stored at $4{ }^{\circ} \mathrm{C}$ until further use.

\section{RP-HPLC analysis}

RP-HPLC analysis of phenolic compounds was performed on Jasco chromatographic system (Model no. LC-2000 Plus) equipped with a quaternary pump, autosampler, and UV detector (UV 2070). The separation was performed using Hiber C18 column (5 $\mu \mathrm{m}, 250-4,6$ $\mathrm{mm}$ ). The built in ChromNAV software system was used for data processing. The mobile phase consisted of water: acetonitrile: glacial acetic acid (90:5:5) was used with $0.9 \mathrm{ml} / \mathrm{min}$ flow rate and $20 \mu \mathrm{l}$ injection volume. The peaks were monitored at $280 \mathrm{~nm}$ with $50 \mathrm{~min}$ as run time. The identification of phenolic compounds in extracts was performed by comparing their retention times with those of standards. Identified phenolics were confirmed by spiking with known concentration of the respective standard. A standard curve of selected phenolics with four different concentrations (25-200 $\mu \mathrm{g} / \mathrm{ml}$ ) was prepared and expressed as micrograms per gram of dry weight (mg/g DW). The system suitability was assessed by triplicate injection of standard solutions and extracts. The peak areas of three replicate injections of standard solutions and extracts were considered to evaluate the repeatability of the method. All solutions (mixed standards, samples and spiked solutions) were filtered through $0.22 \mu \mathrm{m}$ nylon syringe filter.

\section{Statistical analysis}

All the analyses were done in triplicate and values are represented as mean \pm standard error (SE). The data were subjected to one-way analysis of variance (ANOVA) and significant differences between mean values were determined by Duncan's multiple range test (DMRT) $(p<0.05)$ using SPSS version 16.0.

\section{RESULTS AND DISCUSSION}

\section{Total phenolics}

Phenolics are a natural group of secondary metabolites that effectively scavenge free radicals from a biological system. It was found that high content of phenolics linearly correlated with high antioxidant activity [22]. Phenolics have been receiving much more attention among researcher and consumer for its diverse health benefits. Apart from these, it possesses anticarcinogenic, antiatherogenic, anti-inflammatory, antimicrobial properties $[6,23]$. In the present investigation, we found that methanol extract of leaf and fruit showed higher phenolic content $(7.51 \pm 0.08$ and $9.29 \pm 0.01$ $\mathrm{mg} \mathrm{TAE} / \mathrm{g}$ extract) (table 1). Aqueous extract of leaf and fruit exhibited moderate and hexane and chloroform extract showed least phenolics content. The results are agreed with Kumari [24] who found that methanol extract of Pithecellobium dulce leaves recorded relatively higher level of total phenols ( $88.2 \mathrm{mg} \mathrm{GAE} / \mathrm{g}$ dry weight).

\section{Total tannins}

Tannins are high molecular weight phenolics with multiple biological activities like metal ion chelation, protein precipitation and considered as natural antioxidants. It has been reported that tannins are more effective antioxidant than low molecular weight phenolics [25].

Table 1: Extract yield, total phenolics, total tannins, total flavonoids and total terpenoids content of leaf and fruit extracts of $D$. palmatu

\begin{tabular}{|c|c|c|c|c|c|c|c|c|}
\hline \multirow[t]{2}{*}{ Phytochemicals } & \multicolumn{4}{|l|}{ Leaf extract } & \multicolumn{4}{|l|}{ Fruit extract } \\
\hline & Hexane & Chloroform & Methanol & Aqueous & Hexane & Chloroform & Methanol & Aqueous \\
\hline Extract yield $^{1}$ & 1.76 & 0.99 & 1.50 & 9.37 & 2.17 & 0.85 & 1.25 & 8.95 \\
\hline Total phenolics ${ }^{2}$ & $0.66 \pm 0.01^{\mathrm{e}}$ & $0.85 \pm 0.02^{\mathrm{d}}$ & $7.51 \pm 0.08^{b}$ & $1.74 \pm 0.00^{c}$ & $0.36 \pm 0.00^{f}$ & $0.67 \pm 0.00^{\mathrm{e}}$ & $9.29 \pm 0.01^{\mathrm{a}}$ & $1.82 \pm 0.00^{c}$ \\
\hline Total tannins ${ }^{3}$ & $4.83 \pm 0.04^{\mathrm{d}}$ & $22.07 \pm 0.06^{a}$ & $7.56 \pm 0.21^{b}$ & $4.56 \pm 0.10^{\mathrm{d}}$ & $0.70 \pm 0.05^{\mathrm{f}}$ & $6.99 \pm 0.13^{c}$ & $2.97 \pm 0.05^{\mathrm{e}}$ & $0.94 \pm 0.04^{\mathrm{f}}$ \\
\hline Total flavonoids $^{3}$ & $0.98 \pm 0.12^{\mathrm{f}}$ & $2.44 \pm 0.27 \mathrm{e}$ & $7.95 \pm 0.21^{\mathrm{c}}$ & $9.55 \pm 0.65^{b}$ & $1.86 \pm 0.08^{\mathrm{e}}$ & $2.51 \pm 0.30^{\mathrm{e}}$ & $15.02 \pm 0.96^{\mathrm{a}}$ & $4.38 \pm 0.02^{\mathrm{d}}$ \\
\hline Total terpenoids 4 & $112.60 \pm 3.37 \mathrm{e}$ & $186.04 \pm 2.48^{c}$ & $227.77 \pm 1.78^{b}$ & $38.25 \pm 1.56^{\mathrm{g}}$ & $84.63 \pm 1.26^{\mathrm{f}}$ & $137.20 \pm 2.28^{\mathrm{d}}$ & $276.73 \pm 0.76^{a}$ & $29.49 \pm 0.96^{\mathrm{h}}$ \\
\hline
\end{tabular}

${ }^{1} \%$ of dry extract, ${ }^{2} \mathrm{mg} \mathrm{TAE} / \mathrm{g}$ extract, ${ }^{3} \mathrm{mg} \mathrm{CE} / \mathrm{g}$ extract, ${ }^{3} \mathrm{mg} \mathrm{UAE} / \mathrm{g}$ extract. Values are the means of three replicates \pm SE. Mean values with different alphabets showed statistically significant differences $(\mathrm{p}<0.05)$ according to DMRT.

In our results, irrespective of solvent used the leaf extract showed higher tannins content than fruit extract except for chloroform (table 1). Total tannin content of chloroform leaf extract was higher $(22.07 \pm 0.06 \mathrm{mg}$ $\mathrm{CE} / \mathrm{g}$ extract) than methanol, hexane and aqueous leaf extract. Similarly, chloroform fruit extract contained significantly higher tannins (6.99 $\pm 0.10 \mathrm{mg} \mathrm{CE} / \mathrm{g}$ extract) than other fruit extracts. The results are comparable with Cucumis dipsaceus fruit [26].

\section{Total flavonoids}

Flavonoids are a most common group of antioxidants. Due to their high redox potential, they act as singlet oxygen quenchers, reducing agents, hydrogen donors and metal chelator [27]. In our analysis, fruit extract showed higher flavonoids content than leaf except for aqueous leaf extract (table 1). Aqueous extract of leaf and methanol extract of fruit showed higher flavonoids content $(9.55 \pm 0.65$ and $15.02 \pm 0.96 \mathrm{mg} \mathrm{CE} / \mathrm{g}$ extract) compared to other extract. Archana and Vijayalakshmi [28] recorded a considerable amount of flavonoids in ethanol root extract of Glycyrrhiza glabra.

\section{Total terpenoids}

Terpenoids are the largest and diverse group of compounds and served as a growth regulator, pollinator attractants, antifeedants, toxins and antioxidant [29]. Many of which are efficient in the treatment of human diseases like cancer, malaria, inflammation and a variety of viral and bacterial diseases [30]. In present study, highest terpenoids were recorded in methanol leaf and fruit extract
(227.77 \pm 1.78 and $276.73 \pm 0.76 \mathrm{mg} \mathrm{UAE} / \mathrm{g}$ extract) while least were observed in aqueous leaf and fruit $(38.25 \pm 1.56$ and $29.49 \pm 0.96 \mathrm{mg}$ UAE/g extract respectively) (table 1).

\section{Antioxidant assays}

DPPH radical scavenging activity

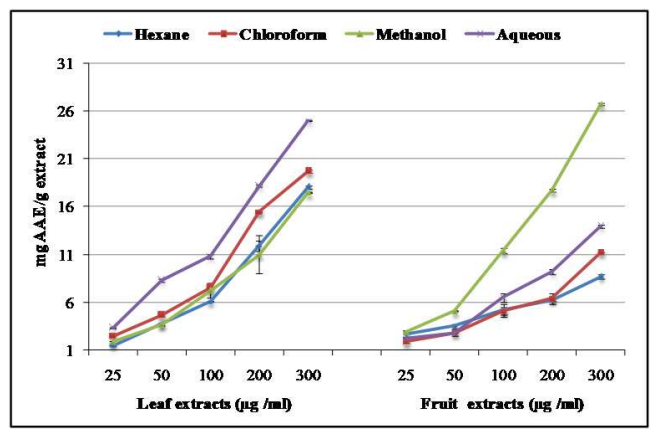

Fig. 1: DPPH· radical scavenging activity of leaf and fruit extracts of $D$. palmatus. Values were the means of three replicates $\pm \mathrm{SE}$

The method is based on the reduction of DPPH radical by antioxidant and then form of more stable DPPH molecule [17]. 
Methanolic solution of DPPH is with deep violet color that showed a strong absorption at $517 \mathrm{~nm}$. The absorption decreases as a result of a change in color from violet to yellow due to DPPH radical scavenged by the plant antioxidant. In the present study, among leaf extracts, water $(25.01 \pm 0.07 \mathrm{mg} \mathrm{AAE} / \mathrm{g}$ extract) showed a higher level of radical scavenging activity. On the other hand, in fruit, methanol extract found better $(26.73 \pm 0.14 \mathrm{mg} \mathrm{AAE} / \mathrm{g}$ extract). In leaf, the order of scavenging capacity in the extract was aqueous $>$ chloroform $>$ hexane $>$ methanol. However, in fruit extract, the order of scavenging capacity was methanol>aqueous $>$ chloroform $>$ hexane (fig. 1). Our results are also in good agreement with Kumari [24] who confirmed that methanol extract of Pithecellobium dulce leaves ( $\mathrm{IC}_{50} 74.89 \mu \mathrm{g} / \mathrm{ml}$ ) showed significant DPPH radical scavenging activity.

\section{ABTS radical scavenging activity}

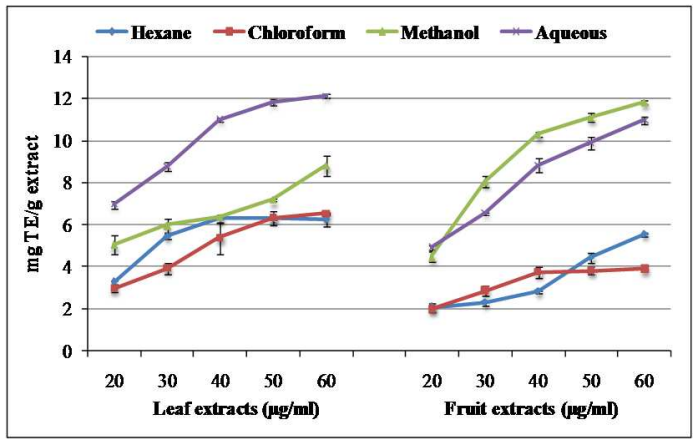

Fig. 2: ABTS+radical scavenging activity of leaf and fruit extracts of D. palmatus. Values were the means of three replicates $\pm S E$

ABTS radical scavenging assay is an excellent tool for determining the antioxidant activity [31]. In this assay, the green color of ABTS radical solution gradually vanishes and became colorless due to the reduction of ABTS radical by antioxidant [18]. In our study, methanol and aqueous extracts of leaf showed higher radical scavenging capacity $(8.81 \pm 0.49$ and $12.11 \pm 0.07 \mathrm{mg} \mathrm{TE} / \mathrm{g}$ extract). Similarly, fruit extracted with methanol and water showed highest radical scavenging activity $(11.81 \pm 0.07$ and $10.96 \pm 0.17 \mathrm{mg}$ TE/g of extract) while chloroform and hexane extract registered with least radical scavenging activity (fig. 2). These results are concurred with Nivedhini et al. [26] wherein methanol extract of Cucumis dipsaceus fruit showed higher ABTS radical scavenging activity against chloroform.

\section{Metal chelating activity}

The metal ion is a natural constituent of every biological system, but excess or exposure to certain metal ions induces the generation of ROS. These ROS causes oxidative deterioration of biological macromolecules and enhances risk of various diseases. Hence, antioxidants protect the biological system either by trapping free radicals or by chelating metal ion [32].

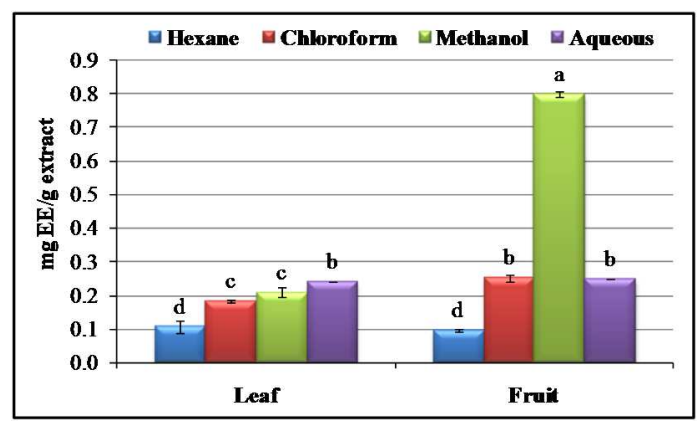

Fig. 3: Metal chelating activity of leaf and fruit extracts of $D$. palmatus. Values are the means of three replicates \pm SE. Mean values with different alphabets showed statistically significant differences $(p<0.05)$ according to DMRT
In the present investigation, aqueous leaf extract showed higher activity $(0.24 \pm 0.001 \mathrm{mg} \mathrm{EE} / \mathrm{g}$ extract). Among fruit extracts, methanol exhibited higher activity $(0.80 \pm 0.008 \mathrm{mg} \mathrm{EE} / \mathrm{g}$ extract). Taking everything into account, the fruit extracts showed highest metal chelating activity (fig. 3). Similarly, Nivedhini et al. [26] reported that methanol extract of Cucumis dipsaceus fruit exhibited higher chelating activity (12.4 mg EDTA equivalent/g extract).

\section{FRAP assay}

FRAP assay is based on the ability of antioxidant compounds to reduce the TPTZ-Fe(III) complex to the intensely blue colored TPTZ-Fe(II) complex in acidic medium with maximum absorption at $593 \mathrm{~nm}$.

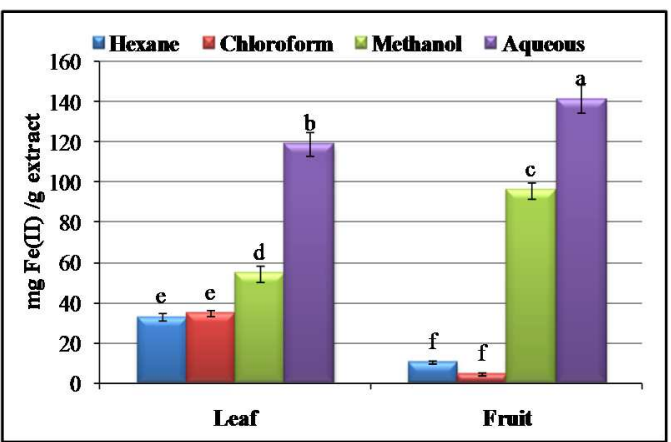

Fig. 4: FRAP activity of leaf and fruit extracts of D. palmatus Values are the means of three replicates \pm SE. Mean values with different alphabets showed statistically significant differences $(p<0.05)$ according to DMRT

Generally reducing properties are related with the presence of reductant compounds that inactivate the oxidant by donating electrons [33]. The results indicated that aqueous extract of both leaf and fruit exhibited significantly higher FRAP value $(118.90 \pm 6.37$ and $141.54 \pm 10.12 \mathrm{mg}$ Fe (II) equivalent/g extract) compared to other extracts. Methanolic extracts of leaf and fruit registered with moderate FRAP value $(54.49 \pm 0.75$ and $95.97 \pm 4.30 \mathrm{mg}$ Fe (II) equivalent/g extract). However, lower FRAP values were recorded in the chloroform and hexane leaf and fruit extracts (fig. 4). Irshad et al. [34] reported that aqueous fruit extract of Luffa cylindrica showed significant antioxidant activity than other cucurbits extracts.

\section{Phosphomolybdenum assay}

The antioxidant capacities of different extracts were evaluated and results are depicted in fig. 5 . It is based on the reduction of Mo (VI to Mo $V$ ) by antioxidants and subsequent formation of a green color phosphate-Mo (V) complex that show maximum absorption at 695 $\mathrm{nm}$ [21]. In our study, leaves extracted with water showed significantly higher antioxidant activity $(133.56 \pm 3.00 \mathrm{mg} \mathrm{AAE} / \mathrm{g}$ extract) than another solvent extract. On the other hand, in fruit, methanol extract showed highest antioxidant activity $(291.24 \pm 2.19$ $\mathrm{mg} \mathrm{AAE} / \mathrm{g}$ extract). In leaf, the order of antioxidant capacity was aqueous $>$ methanol $>$ chloroform $>$ hexane.

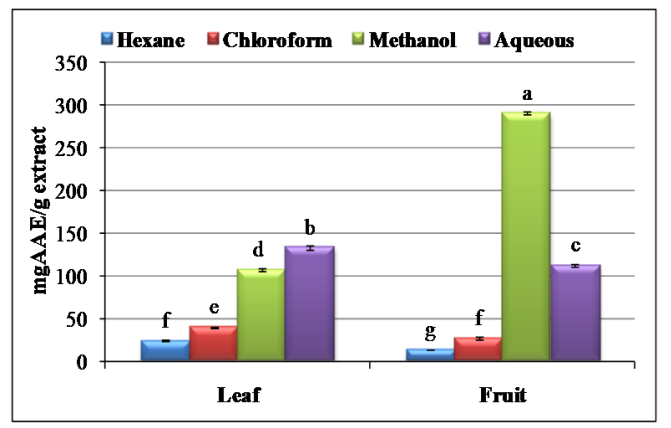

Fig. 5: Phosphomolybdenum reduction assay of leaf and fruit extracts of $D$. palmatus Values are the means of three replicates $\pm S E$. Mean values with different alphabets showed statistically significant differences $(p<0.05)$ according to DMRT 
Likewise, in fruit the trend was methanol>aqueous>chloroform> hexane. Highly polar solvents exhibited the higher antioxidant activity in M. charantia var. charantia [35].

\section{Qualitative and quantitative analysis of phenolic compounds}

In the present analysis, phenolics compounds such as GA, CA, HBA, CLA and VA were identified and quantified from methanol extracts of leaf and fruit (table 2, fig. 6 and 7).

Our results revealed that CA $(4.74 \pm 0.26 \mathrm{mg} / \mathrm{g} \mathrm{DW})$ was the major phenolic compound in leaf followed by HBA $(2.21 \pm 0.06$ $\mathrm{mg} / \mathrm{g} \mathrm{DW})$ and CLA $(1.72 \pm 0.14 \mathrm{mg} / \mathrm{g}$ DW). However, GA and VA were noted with minor quantities in leaf. In fruit extract, CLA $(2.14 \pm 0.01 \mathrm{mg} / \mathrm{g} \mathrm{DW})$ was predominant phenolic compound while GA $(0.93 \pm 0.05 \mathrm{mg} / \mathrm{g}$ DW), HBA $(1.19 \pm 0.08 \mathrm{mg} / \mathrm{g} \mathrm{DW})$ and VA $(0.79 \pm 0.02 \mathrm{mg} / \mathrm{g}$ DW) were noted with least amount.

It is proved that phenolics compounds are the potential antioxidants and having several health benefits like antimutagenic, anticarcinogenic, anti-cancer and anti-diabetic [36]. All phenolics compounds identified in this study are a potent free radical scavenger as well as effective in the prevention of several diseases.

Table 2: Phenolic compounds in the methanol extracts of leaf and fruit $\mathrm{D}$. palmatus

\begin{tabular}{lllll}
\hline S. No. & Phenolic compounds & Retention time & Leaf (mg/g dry weight) & Fruit (mg/g dry weight) \\
\hline 1. & GA & 4.383 & $0.56 \pm 0.02$ & $0.93 \pm 0.05$ \\
2. & CA & 10.433 & $4.74 \pm 0.26$ & - \\
3. & HBA & 12.625 & $2.21 \pm 0.06$ & $1.19 \pm 0.08$ \\
4. & CLA & 15.167 & $1.72 \pm 0.14$ & $2.14 \pm 0.01$ \\
5. & VA & 19.125 & $0.73 \pm 0.02$ & $0.79 \pm 0.02$ \\
\hline
\end{tabular}

Values are the means of three replicates \pm SE.

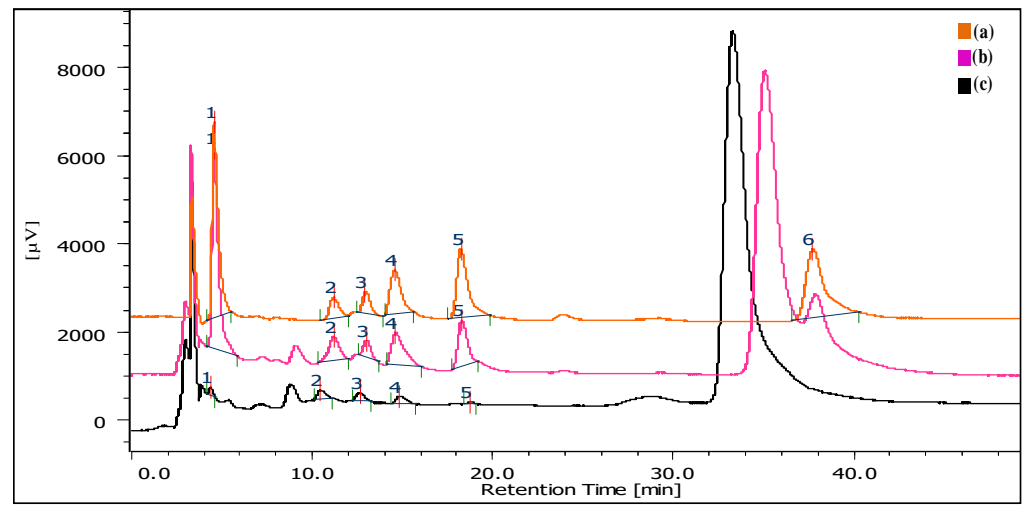

Fig. 6: HPLC chromatograms a) Mixture of standard phenolics compounds 1) GA 2) CA, 3) HBA, 4) CLA, 5) VA; 6) COA; b) Crude extract of leaf of $D$. palmatus spiked with above mention standard compounds; C) Crude extract of leaf of $D$. palmatus where the peaks were identified as follows: 1) GA, 2) CA, 3) HBA, 4) CLA, 5) VA

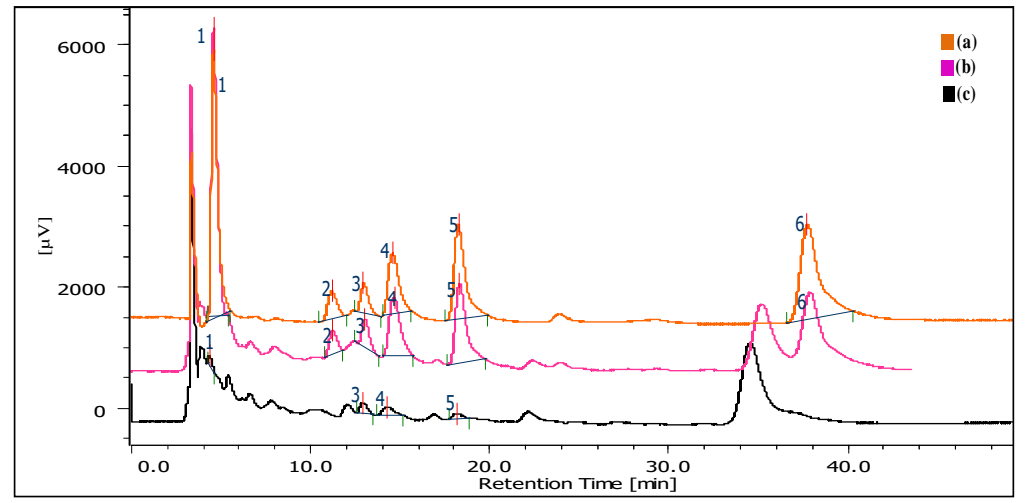

Fig. 7: HPLC chromatograms a) Mixture of standard phenolics compounds 1) GA, 2) CA, 3) HBA, 4) CLA, 5) VA, 6) COA; b) Crude extract of fruit of $D$. palmatus spiked with above mention standard compounds; C) Crude extract of fruit of $D$. palmatus where the peaks were identified as follows: 1) GA, 3) HBA, 4) CLA, 5) VA

\section{CONCLUSION}

In this study, the phytochemical analysis of D. palmatus indicated the presence of bioactive metabolites in leaf and fruit. The methanolic extract of fruit and aqueous extracts of leaf displayed appreciable antioxidant potential. Leaf and fruit extracts of D. palmatus were determined to have a certain level of radical scavenging effect, proportional to their level of phytochemicals.
In addition, the polar solvent mainly methanol showed stronger radical scavenging effect. The characterization of phenolics compounds revealed that antioxidant ability of D. palmatus is partially due to the presence of phenolics compounds.

Further, the isolation and characterization of bioactive compounds is needed for their use in food and pharmaceutical industries. 


\section{ACKNOWLEDGMENT}

Authors are grateful to Science and Engineering Board (SERB), New Delhi (Sanction order no. SB/EMEQ-460/2014) and Shivaji University, Kolhapur for their financial support.

\section{AUTHOR CONTRIBUTION}

Usmangani A. attar and Savaliram G. Ghane contributed equally in the collection of plant material, experiment design, performing the experiment, data compilation and statistical analysis. Both the authors wrote, read and approved the final manuscript.

\section{CONFLICT OF INTERESTS}

\section{Declared none}

\section{REFERENCES}

1. Goun E, Cunningham G, Chu D, Nguyen C, Miles D. Antibacterial and antifungal activity of Indonesian ethnomedical plants. Fitoterapia 2003;74:592-6.

2. Cai YZ, Sun M, Corke H. Antioxidant activity of betalains from plants of the Amaranthaceae. J Agric Food Chem 2003;51:2288-94.

3. Gramza-Michałowska A, Czlapka-Matyasik M. Evaluation of the antiradical potential of fruit and vegetable snacks. Acta Sci Pol Technol Aliment 2011;10:61-72.

4. Zhang WM, Li B, Han L, Zhang HD. Antioxidant activities of extracts from areca (Areca catectu L.) flower husk and seed. Afr J Biotechnol 2009;8:3887-92.

5. Gupta VK, Sharma SK. In vitro antioxidant activities of aqueous extract of Ficus bangalensis Linn Root. Int J Biol Chem 2010;4:134-40.

6. Scalbert A, Johnson IT, Saltmarsh M. Polyphenols: antioxidants and beyond. Am J Clin Nutr 2005;81:215-7.

7. Krishnarajua AV, Rao TVN, Sundararajua D, Vanisreeb M, Tsayb $\mathrm{H}$, Subbaraju GV. Assessment of bioactivity of Indian medicinal plants using Brine Shrimp (Artemia salina) lethality assay. Int J Appl Sci Eng 2005;3:125-34.

8. Singh V, Malviya T. A non-ionic glucomannan from the seeds of an indigenous medicinal plant: Bryonia lacinosa. Carbohydr Polym 2006;64:481-3.

9. Kadam P, Bodhankar S. Analgesic and anti-inflammatory activity of seed extracts of Diplocyclos palmatus (L) C. Jeffrey. Int J Pharma Bio Sci 2013a;4:970-8.

10. Kadam P, Bodhankar S. Antiarthritic activity of ethanolic seed extracts of Diplocyclos palmatus (L) C. Jeffrey in experimental animals. Der Pharm Lett 2013b;5:233-42.

11. Devi TS, Padmaja IJ, Harshitha C, Kalyani CS, Lakshmi N, Bhavani AKD. Anti dermatophytic activity on ethnomedical plants used by a primitive tribe "Gadabas" of Paderu. Int J Pharm Bio Sci 2014;5:292-9.

12. Gupta P, Wagh RD. A review on morphology, phytochemistry, pharmacology and folklore uses of Diplocyclos palmatus (L.) Jeffry. Int J Pharm Life Sci 2014;5:3622-6.

13. Singleton VL, Rossi JA. Colorimetry of total phenolics with phosphotungstic acid reagents. Am J Enol Vitic 1965;16:144-58.

14. Bhat R, Sridhar KR, Yokotani KT. Effect of ionising radiation on antinutritional features of velvet bean seeds (Mucuan pruriens). Food Chem 2007;103:860-6.

15. Sakanaka S, Tachibana Y, Okada Y. Preparation and antioxidant properties of extracts of Japanese persimmon leaf tea (Kakinoha-cha). Food Chem 2005;9:569-75.

16. Chang CL, Lin CS. Phytochemical composition, antioxidant activity and neuroprotective effect of Terminalia chebula Retzius extract. J Evidence-Based Complementary Altern Med 2011. Doi:10.1155/2012/125247.

17. Brand-Williams W, Cuvelier ME, Berset C. Use of free radical method to evaluate antioxidant activity. Lebanon Wissen Technol 1995;28:25-30.
18. Re R, Pellegrini N, Proteggente A, Pannala A, Yang $M$, Rice-Evans C. Antioxidant activity applying an improved ABTS radical cation decolorization assay. Free Radical Biol Med 1999;26:1231-7.

19. Dinis TCP, Madeira VMC, Almeida LM. The action of phenolics derivatives (acetaminophen, alicylate, and 5-amino salicylate) as inhibitors of membrane lipid peroxidation and as peroxyl radical scavengers. Arch Biochem Biophys 1994;315:161-9.

20. Benzie IFF, Strain JJ. The ferric reducing ability of plasma (FRAP) as a measure of "Antioxidant power" The FRAP assay. Anal Biochem 1996;239:70-6.

21. Prieto P, Pineda M, Aguilar M. Spectrophotometric quantitation of antioxidant capacity through the formation of a phosphomolybdenum complex: specific application to the determination of vitamin E. Anal Biochem 1999;269:337-41.

22. Roya K, Fatemeh G. Screening of total phenol and flavonoid content, antioxidant and antibacterial activities of the methanolic extracts of three Silene species from Iran. Int J Agric Crop Sci 2013;5:305-12.

23. Duthie GG, Gardner PT, Kyle JAM. Plant polyphenols: are they the new magic bullet? Proc Nutr Soc 2003;62:599-603.

24. Kumari S. Evaluation of phytochemical analysis and antioxidant and antifungal activity of Pithecellobium dulce leaves extract. Asian J Pharm Clin Res 2017;10:370-5.

25. Yokazawa T, Chen CP, Dong E, Tanaka T, Nonaka GI, Nishioka I. Study on the inhibitory effect of tannins and flavonoids against the 1,1-diphenyl-2-picrylhydrazyl radical. Biochem Pharmacol 1998;56:213-22.

26. Nivedhini V, Chandran R, Parimelazhagan T. Chemical composition and antioxidant activity of Cucumis dipsaceus Ehrenb. Ex Spach fruit. Int Food Res J 2014;21:1465-72.

27. Cao G, Sofic E, Prior RL. Antioxidant and prooxidant behaviour of flavonoids: structure-activity relationships. Free Radical Biol Med 2009;22:749-60.

28. Archana I, Vijayalakshmi K. Preliminary phytochemical screening and in vitro free radical scavenging activity of root extracts of Glycyrrhiza glabra L. Asian J Pharm Clin Res 2016;9:85-90.

29. Gershenzon J, Dudareva N. The function of terpene natural products in the natural world. Nat Chem Biol 2007;3:408-14.

30. Dillard CJ, German JB. Phytochemicals: nutraceuticals and human health. J Sci Food Agric 2000;80:1744-56.

31. Leong LP, Shui G. An investigation of antioxidant capacity of fruits in Singapore markets. Food Chem 2002;76:69-75.

32. Flora SJS. Structural, chemical and biological aspects of antioxidants for strategies against metal and metalloid exposure. Oxid Med Cellular Longev 2009;2:191-206.

33. Pulido R, Bravo L, Sauro-Calixo F. Antioxidant activity of dietary polyphenols as determined by a modified ferric reducing/antioxidant power assay. J Agric Food Chem 2000;48:3396-402.

34. Irshad M, Ahmad I, Mehndi SG, Goel HC, Rizvi MMA. Antioxidant capacity and phenolic content of the aqueous extract of commonly consumed cucurbits. Int J Food Prop 2014;17:179-86.

35. Biswas S, Dasgupta N, De B. Antioxidant activity of some Indian medicinal plants used for the treatment of diabetes mellitus. Pharmacol Online 2010;3:7-21.

36. Wang Z, Loo WT, Wang N, Chow LW, Wang D, Han F, et al. Effect of Sanguisorba officinalis L. on breast cancer growth and angiogenesis. Exp Opin Ther Targets 2012;1:79-89.

\section{How to cite this article}

- Usmangani A Attar, Savaliram G Ghane. Phytochemicals, antioxidant activity and phenolic profiling of diplocyclos palmatus (L.) C. jeffery. Int J Pharm Pharm Sci 2017;9(4):101-106. 